Universidade de Brasília

Centro de Excelência em Turismo

\title{
POTENCIAL TURÍSTICO DO LAGO PARANOÁ PESCA ESPORTIVA
}

\section{Adley Evangelista Ramos dos Anjos}

Orientadora: Carmen Regina Mendes de Araújo Correia

Monografia apresentada ao Centro de Excelência em Turismo da Universidade de Brasília como requisito parcial para a obtenção do certificado de Especialista em Ecoturismo.

Brasília, DF, Agosto 2004. 
Universidade de Brasília

Centro de Excelência em Turismo

Curso de Especialização em Ecoturismo

\section{POTENCIAL TURÍSTICO DO LAGO PARANOÁ PESCA ESPORTIVA}

\section{Adley Evangelista Ramos dos Anjos}

Banca Examinadora

Carmen Regina Mendes de Araújo Correia, $\mathrm{Dr}^{\mathrm{a}}$. em Ecologia

Membro da Banca

Brasília, DF, 02 de Agosto de 2004. 
Anjos, Adley Evangelista Ramos dos.

Potencial turístico do Lago Paranoá - Pesca esportiva/Adley Evangelista Ramos dos Anjos.

$34 \mathrm{f}$.

Monografia (especialização) - Universidade de Brasília. Centro de Excelência em Turismo. Brasília, 2004.

Área de concentração: Turismo

Orientadora: Carmen Regina Mendes de Araújo Correia

1. Ecoturismo 2. Lago Paranoá 3. Pesca Esportiva 
Adley Evangelista Ramos dos Anjos

\section{POTENCIAL TURÍSTICO DO LAGO PARANOÁ PESCA ESPORTIVA}

Comissão Avaliadora

Carmen Regina Mendes de Araújo Correia

Brasília, DF, 02 de Agosto de 2004. 
Dedico este trabalho a minha irmã Alda e ao meu esposo Valério. 


\section{Sumário}

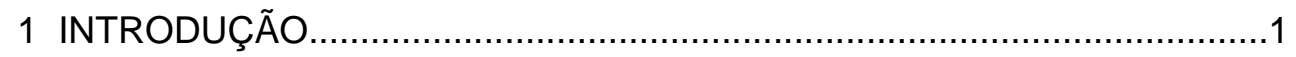

2. REVISÃO BIBLIOGRÁFICA …......................................................

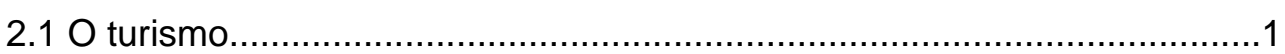

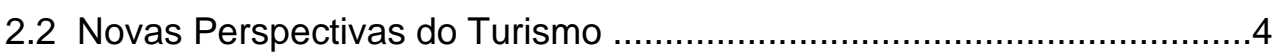

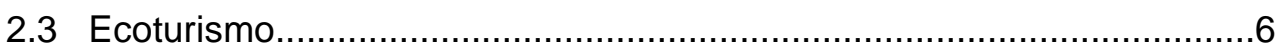

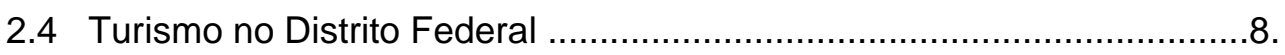

2.5 Pesca Esportiva - Atividade Turística Sustentável................................10

2.6 Aspectos Ecológicos do Lago Paranoá...................................................14

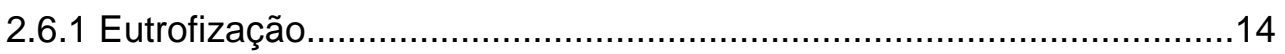

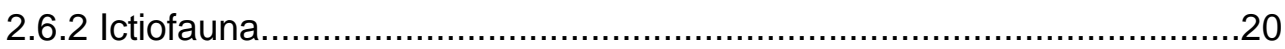

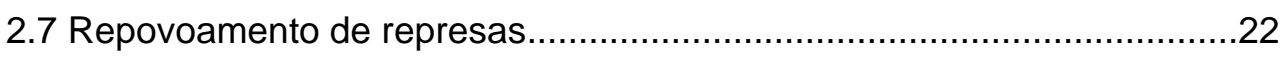

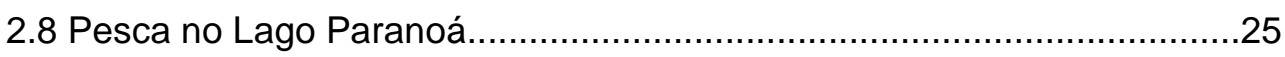

2.9 Legislação Federal sobre a Pesca...................................................... 27

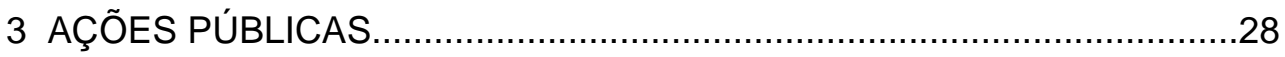

4 CONSIDERAÇÕES FINAIS.........................................................

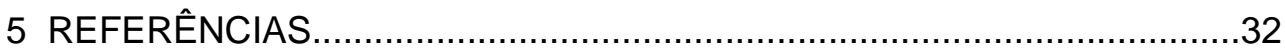


Resumo

O Ecoturismo tem sido visto como uma alternativa de desenvolvimento para a região do Distrito Federal. Nesse aspecto, o Lago Paranoá se associa com destaque à demanda turística e, de certa forma, favorece uma série de atividades econômicas junto à comunidade local. Dentre estas atividades destaca-se a pesca esportiva, tema dessa pesquisa, que, se enfocada sob uma ótica de produto ecológico e de fortalecimento da economia local, pode constituir mais um instrumento de preservação e enaltecimento dos aspectos naturais.

Embora esteja sofrendo agressões constantes oriundas da atividade humana, o Lago Paranoá é um espaço importante para o desenvolvimento do Ecoturismo. Este permitirá não apenas a construção de mais uma alternativa econômica para a região, mas também um processo de desenvolvimento de infraestrutura e preservação do Lago Paranoá.

Palavras chave: Ecoturismo; Lago Paranoá; Pesca Esportiva, Turismo no Distrito Federal. 


\section{ABSTRACT}

Ecotourism has been seen as a development alternative for the region of Federal District, Brazil. In this regard, the Paranoá Lake is related with prominence to the tourist demand and, in a some way, it exerts a relationship of economical activities with the local community - as sports fishing, theme of this research - for being an ecological product that exalts aspects of the nature.

Although it has been suffering constant aggressions caused by human activities, the Paranoá Lake is an important space for the development of Ecotourism. It will allow not only the construction of one more economical alternative for the region, but also a process of infrastructure development and preservation of the Paranoá Lake.

Keywords: Ecotourism; Paranoá Lake; Tropical Sportive Fishing, Brazil; Federal District, Brasil Tourism. 
OBJETIVO GERAL

Levantar indicadores ambientais visando o aproveitamento do ecoturismo no Lago Paranoá, Distrito Federal, com ênfase nas atividades relacionadas à pesca esportiva.

\section{OBJETIVOS ESPECÍFICOS}

Identificar as características naturais da região apontando os fatores limitantes e favoráveis à implantação da pesca esportiva no Lago Paranoá.

Caracterizar a infra-estrutura de apoio à atividade de pesca esportiva.

Caracterizar a ictiofauna do Lago Paranoá, indicando as espécies potenciais de sustentação da atividade de turismo de pesca esportiva. 


\section{INTRODUÇÃO}

Tornou-se comum fazer apologia ao turismo, tanto nos meios acadêmicos como nos governamentais e na imprensa, dada a sua inegável posição de destaque na economia mundial.

Entre as questões que mais preocupam os estudiosos do turismo estão os problemas da preservação (cultural e de recursos naturais) e planejamento. A falta de consideração efetiva desses aspectos tem sido responsável por danos sem precedentes.

Em meados dos anos 90, diversos órgãos e empresas públicas e privadas demonstraram interesse em desenvolver o turismo brasileiro, bem como no Distrito Federal. Vários incentivos foram fornecidos pelo Governo do Distrito Federal para favorecer as instalações turísticas em todo a região.

O turismo no Distrito Federal apresenta alta potencialidade favorecido pela arquitetura de Brasília e a importância histórica e cultural da capital federal. Todavia, o ecoturismo é bastante incipiente e as políticas públicas, bem como a participação dos agentes locais, não é efetiva no seu desenvolvimento, em especial no que tange ao turismo voltado para a pesca esportiva no Lago Paranoá.

Esta monografia apresenta um conjunto de dados sobre o meio ambiente e o ecoturismo, obtidos por pesquisa bibliográfica, que sejam voltadas ao Lago Paranoá. Pretende-se indicar possibilidades de resoluções econômicas e ambientais que sejam viáveis.

\section{REVISÃO BIBLIOGRÁFICA}

\subsection{Turismo}

Em 1987 foi definido pela Comissão Mundial sobre o Meio Ambiente e Desenvolvimento, na Assembléia Geral das Nações Unidas "o desenvolvimento 
sustentável é necessário para firmar às necessidades do presente sem por em perigo a capacidade das gerações futuras a fim de atender suas necessidades". Segundo Mclytryre:

“(..) para se obter um turismo sustentável o Estado deve fixar políticas, normas e incentivos, estimular e apoiar a conservação da natureza e da proteção cultural e delimitar sítios e zonas protegidas (MCLYTRYRE 1993)".

O turismo pode, ainda, beneficiar a comunidade através da interação cultural, geração de recursos, transferência de tecnologia, educação ambiental, melhor utilização do solo, melhor infra-estrutura, empregos e desenvolvimentos de empresas locais. A comunidade pode, também, desenvolver uma interação cultural, serviços para os visitantes, lazer e produtos locais. "Para muitos países o turismo tem surgido como efeito salvação" (RUSCHMANN 1997).

Em contra-partida, tem-se os efeitos negativos, que são os custos de oportunidade, a dependência excessiva do turismo, a instabilidade, a sazonalidade da demanda turística, a inflação, bem como a especulação imobiliária.

A sua possibilidade de expansão, enquanto atividade econômica, está diretamente relacionada à resolução dos problemas que são gerados no bojo de seu crescimento e cujo enfrentamento passa a se constituir uma questão de vital importância para auferir qualidade aos seus produtos finais, os bens turísticos. Há, portanto, um conflito inerente entre a demanda de crescimento, enquanto setor emergente da economia, e seu caráter eminentemente predatório, que pode perturbar o ritmo com que se dá esse crescimento (NICOLETTI 2003).

O turismo figura-se como um dos fenômenos mais marcantes do mundo contemporâneo, e sua expressividade não se limita ao fato econômico, mas principalmente como fato social, criando e recriando formas espaciais diversificadas. 
Para Beni:

"O turismo é o conjunto de aspectos sociais, econômicos e culturais que provocam e integram o deslocamento das pessoas do local de residência a outro, com o objetivo de permanência temporária e com a finalidade de fruição. Fruição da natureza, do meio social e ecológico (BENI 1998)".

A conceituação e a operacionalização do turismo estão relacionadas com os efeitos positivos sobre a saúde, influência sobre a economia, a geração de empregos, a preservação para as outras sociedades, desenvolvimento de meios educativos e disponibilização de recursos turísticos como os espaços (paisagem), os bens (infra-estrutura, equipamentos e mão de obra) e valores (crenças e costumes).

Entretanto, a atividade do turismo relaciona-se de forma típica com uma periferia de uma área já densamente povoada o que ressalta o papel da geografia para a plena compreensão do espaço. Christaller mostra que:

“(...) a análise das várias ocupações econômicas do espaço pode ser conduzida basicamente de duas maneiras, uma com a idéia abstrata do espaço "puro", e outra com a idéia do espaço "real", equipado com montanhas, planícies, costas e vegetação, isto é, a paisagem (CHRISTALLER 1963)".

O turismo é uma atividade que produz (mesmo quando se apropria sem transformar) um espaço. Valoriza uma determinada paisagem sem que haja uma intervenção para a produção espacial.

Contudo, "o espaço do / ou para o turismo constitui uma mercadoria complexa, pois ele mesmo é uma mercadoria. Trata-se da natureza, ou da produção social, 
incorporada em outra mercadoria, mas com parte do mesmo consumo / produção / do espaço" (YÁZIGI et al. 1996).

\subsection{Novas Perspectivas do Turismo}

O homem urbano tem se deslocado em direção à natureza, em busca de áreas verdes e espaços arborizados cada vez menos acessíveis nas cidades, em uma ação justificada pela necessidade de evasão da vida cotidiana - sem significados imediatos, não individualizados e sujeita a enlouquecedoras rotinas laborais intercaladas pelo tempo de não-trabalho.

Tais fluxos de deslocamentos têm-se assentado sob a denominação de ecoturismo, turismo histórico, ou outras modalidades que, sob a perspectiva de atividade econômica, catalisa as discussões sobre o desenvolvimento sustentável dos meios naturais e culturais, servindo como novo paradigma de organização social, política e econômica das sociedades.

A aventura imaginária do ser humano é sua evasão à natureza, sua necessidade de reencontro com as origens e de comunhão com um passado distante e, muitas vezes, esquecido. É nesta perspectiva que o homem utiliza o cenário natural para o controle e descoberta de novas emoções. Na relação naturezaindivíduo brota a descoberta das próprias potencialidades individuais.

Nesse ambiente, a lógica é substituída pelo desejo de aventura: o reflexo muscular é mais importante que a reflexão filosófica. Os instintos são o elo do homem pós-moderno com suas raízes proto-humanas. É o lúdico ensaio sobre o papel do ócio no processo civilizatório: as atividades do ócio como atividades miméticas por referir-se a sua capacidade em transpor as emoções da vida real em uma dimensão irreal, imaginária. 
Neste cenário, com essas necessidades de evasão a satisfazer, é que se elaboraram as diretrizes para o desenvolvimento do turismo local. Seu objetivo central é o de proporcionar a gestão responsável dos recursos naturais e culturais, bandeira defendida por órgãos públicos, pelas ONG's (organizações nãogovernamentais) e até por muitos representantes da iniciativa privada.

Compete, então, propiciar ações capazes de promover e desenvolver o turismo regional, melhorando as condições de vida das comunidades e preservando o patrimônio de forma racional e planejada, tornando-o uma alternativa real de desenvolvimento sustentável.

Diversificando a economia regional, o turismo deve criar alternativas de valoração econômica nas desgastadas atividades laborais das sociedades receptoras desse fluxo turístico. Ao mesmo tempo, a atividade precisa ser objeto de severo controle, uma vez que o impacto de carga excessiva de turistas pode provocar, tanto os danos ecológicos, como a poluição, quanto o desequilíbrio nas organizações sociais das comunidades receptoras.

Com a recente expansão do turismo, enquanto fenômeno econômico, muitos novos empresários têm adentrado nesse promissor mercado. Entretanto esses empresários não têm tradição em administração de serviços, trazendo sua cultura taylorista para o turismo e, assim, cometendo os erros tradicionalmente encontrados nos demais segmentos econômicos.

Aparentemente a conjuntura do mercado turístico, jovem e em rápido crescimento, irá retardar a aplicação da administração de serviços nesse mercado, mas esses mesmos fatores tornarão inevitável a adoção dessa cultura de gestão, pelas empresas de turismo.

Lembrando Karl Albrecht: 
"Uma cultura de serviço começa com a liderança da empresa. Sobrevive e se desenvolve graças à atenção continuada e o interesse dos administradores de todos os níveis. E dá resultado através dos sentimentos e das ações do pessoal de linha de frente, que é o produto" (ALBRECHT 1992).

A atividade turística, em que os hábitos e costumes são severamente modificados, tem demonstrado enorme capacidade de segmentar-se em conjuntos cada vez mais específicos de necessidades, comportamentos e interesses que deixam o profissional de turismo em dificuldades para estabelecer seus serviços, estruturar a distribuição e elencar prioridades de investimentos.

Dadas essas dificuldades, é imperioso engendrar esforços na tentativa de entender os segmentos de demanda resultantes desta supersegmentação.

\subsection{Ecoturismo}

Uma das modalidades de turismo em expansão é o ecoturismo que traz um novo conceito no que tange ao aproveitamento dos recursos naturais, à saúde e contato com o meio ambiente aliado a processo de conscientização por meio de processos participativos e de educação ambiental (NICOLETTI 2003).

Segundo definição da EMBRATUR, o ecoturismo "é um segmento da atividade turística que utiliza de forma sustentável o patrimônio natural e cultural, incentiva sua conservação e busca a formação de uma consciência ambientalista através da interpretação do ambiente, promovendo o bem estar das populações envolvidas" (EMBRATUR 1999).

O turismo desenvolvido em localidades de potencial ecológico, de forma conservacionista, procurando conciliar a exploração turística com o meio ambiente, 
harmoniza as ações com a natureza e oferece aos turistas um contato com os recursos naturais e culturais da região.

Segundo Amaral:

"(...) o ecoturismo é uma condição muito forte para ajudar os países a se desenvolverem, a criar uma consciência de defesa da natureza" (AMARAL 1995).

Apesar do Brasil possuir uma grande diversidade em paisagens e atrativos naturais, não consegue desenvolver, com honrosas exceções, o ecoturismo, devido ao não planejamento e profissionalização. Para o ecoturismo é de fundamental importância à qualificação nos serviços, já que se trabalha com o meio natural e cultural, necessitando-se do conhecimento e de muitas informações.

As áreas naturais, em particular, as protegidas legalmente, sua paisagem, fauna e flora - juntamente com os elementos culturais existentes -, constituem grandes atrações, tanto para os habitantes do local aos quais as áreas pertencem, como para as demais pessoas. Por este motivo, os poderes instituídos e as sociedades reconhecem a sua enorme importância como fator de desenvolvimento (CEBALLUSLASCURÁIN 2002).

O ecoturismo é uma indústria extremamente ampla e em crescimento em muitos países e tem como uma das suas principais vantagens proporcionar um impulso que favorece tanto a expansão da conservação quanto o desenvolvimento do turismo.

Sob a ótica da conservação, o ecoturismo é o benefício que é mais facilmente vendido e, assim, é com freqüência incorporado nas decisões sobre o uso da terra. Em termos concretos, a cobrança de ingressos e de outras taxas associadas ao ecoturismo podem suplementar os orçamentos governamentais de conservação 
existentes e fornecer incentivos à conservação por intermédio do setor privado. Além disso, geralmente, acredita-se que o ecoturismo exige menos investimentos do setor público em infra-estrutura do que o turismo tradicional (embora possa haver correspondentemente uma quantidade menor de benefícios, resta ainda fazer uma rigorosa avaliação do investimento exigido para cada emprego criado ou para cada dólar em reservas cambiais obtido nos respectivos setores) (LINDBERG e HUBER 2002).

O Ecoturismo no Distrito Federal é caracterizado por belezas cênicas (morros, nascentes, cachoeiras, lagoas, flora variada) atraindo turistas em busca do contato com a natureza, porém, a atividade na região carece de planejamento, definição de produtos, legislação adequada, guias capacitados, infra-estrutura compatível, normas de proteção ambiental, segurança, etc.

\subsection{Turismo no Distrito Federal}

GAMA (2001) fez uma radiografia esclarecedora e sucinta do potencial do turismo para a cidade de Brasília destacando que a cidade reúne condições ideais para o desenvolvimento do turismo de eventos, turismo cívico, turismo arquitetônico, turismo rural, turismo místico e religioso, ecoturismo e o turismo náutico.

Pesa a seu favor, a sua arquitetura construída por JK e planejada por Niemeyer e Lúcio Costa, que já conquistou o mundo com sua imagem de cidade moderna, de arquitetura arrojada, com grandes espaços verdes e um céu esplendoroso, tendo sido declarada pela Unesco como Patrimônio Cultural da Humanidade (GAMA 2001), podendo captar de forma extraordinária a sede de grandes eventos.

A integração do Lago Paranoá a um plano turístico para o DF tornou-se possível por meio do Projeto Orla, no qual estava consubstanciada a democratização do uso e acesso da população ao Lago Paranoá visando ao aproveitamento das condições excepcionais para exploração turística e de lazer que o lago oferece, aliado ao fato 
de que Brasília possui 10.400 embarcações cadastradas na Delegacia Fluvial, constituindo-se na terceira maior frota de barcos do País e maior número per capta de embarcações (um barco para cada oito pessoas) (GAMA 2001).

O Projeto Orla, embora tivesse o objetivo de integrar a cidade ao lago, ao conceber a divisão da orla em 11 grandes pólos a serem explorados comercialmente, deixou de contemplar o pequeno usuário, não oferecendo recursos simples como rampa de acesso a quem queria colocar seu barco na água para um passeio nas águas do Paranoá, sendo possível apenas, via clubes, pagando taxa de aluguel.

A construção das marinas públicas em pontos estratégicos encorajaria o surgimento de novas embarcações para passeios turísticos e mesmo para transporte de passageiros, que poderiam deslocar-se de um ponto a outro do Lago Paranoá, oferecendo conforto e segurança aos seus usuários. A complementação do acesso público se daria pela criação de linhas regulares de ônibus nos pontos de atração do lago, complementando o sistema de transporte. A proposta inicial foi deslocada promovendo-se a implantação de áreas de lazer para o público de maior poder aquisitivo, com a instalação de shoppings (Pier 21, Pontão do Lago Sul, entre outros), com a finalização dependente da iniciativa privada (GAMA 2001, OLIVA et al. 2001).

O incentivo à vocação do Lago para a prática de esportes náuticos necessita da captação de grandes eventos esportivos com a inclusão de Brasília no calendário nacional e internacional de competições náuticas, implantação de infra-estrutura turística de apoio, como mirantes, restaurantes panorâmicos, um circuito gastronômico, comércios e serviços voltados para atender aqueles que se dirigem para a orla do lago, além da recuperação e revitalização dos espaços culturais existentes na orla como a Concha Acústica, o Museu de Arte de Brasília, a Ermida Dom Bosco, dentre outros. 


\subsection{Pesca Esportiva - Atividade Turística Sustentável}

A Lei 9.605, 13.2.1998, que disciplina os crimes contra o meio ambiente, prevendo delitos referentes à pesca (art.34 ao 36), considera a atividade da pesca todo ato tendente a retirar, extrair, coletar, apanhar, apreender ou capturar espécimes dos grupos dos peixes, crustáceos, moluscos e vegetais hidróbios, suscetíveis ou não de aproveitamento econômico, ressalvadas as espécies ameaçadas de extinção, constantes nas listas oficiais da fauna e flora (art.36).

Por sua vez, a regulamentação da atividade da pesca, dada pelo Decreto-lei $\mathrm{n}^{\circ}$ 221, de 28.6.1967 e posteriores alterações, a define como todo ato tendente a capturar ou extrair elementos animais ou vegetais que tenham na água seu normal ou mais freqüente meio de vida (art. $1^{\circ}$ ), podendo ser efetuada com fins comerciais, desportivos ou científicos $\left(\operatorname{art} .2^{\circ}\right)$. Pesca desportiva ou esportiva é a que se pratica com linha de mão ou aparelho permitido pela autoridade competente, desde que não importe em atividade comercial ( $\$ 2^{\circ}$ do art. $2^{\circ}$, do citado Decreto).

A pesca esportiva é uma das atividades de lazer mais praticadas em todo o mundo e, no Brasil, tem apresentado um crescimento vertiginoso, se mostrando um ramo do turismo com enorme potencial de geração de renda. Na atualidade, em algumas localidades, movimenta milhões de dólares e alavanca a industria hoteleira e a de serviços, gerando empregos em outras atividades comerciais e industriais paralelas de apoio ou dependentes (GUIA BRASILEIRO DE PESCA AMADORA 1999).

Para termos uma medida de comparação da importância do segmento da pesca, conforme se extrai do guia anteriormente citado, nos EUA o turismo da pesca amadora, segundo informações da National Survey of Fishing, Hunting and Wildlife, movimenta cerca de 37 bilhões de dólares em atividades diretamente ligadas à pesca esportiva, existindo cerca de 37,5 milhões de pescadores esportivos 
licenciados, cuja demanda de serviços gera cerca de 1.200.000 (um milhão e duzentos mil) empregos diretos.

Neste contexto, o gerenciamento que países como Estados Unidos, Canadá, Argentina, Chile, Costa Rica e Nova Zelândia têm realizado no setor da pesca esportiva demonstra que a atividade é capaz de gerar receitas significativas viabilizando recursos não só para o seu próprio desenvolvimento como também para aplicação em outros setores como turismo e meio ambiente (GUIA BRASILEIRO DE PESCA AMADORA 1999).

A pescaria esportiva, além de ser um salutar prazer ou hobbie, é importante como fator de fuga dos problemas da cidade e do estresse, tendo este esporte crescido muito nas últimas décadas, basta ver os inúmeros programas turísticos de pesca, os pesque e pague, os programas de televisão, as feiras de pesca e as publicações de revistas neste ramo.

Segundo MÉLEGA (1998), a pesca esportiva no Brasil já começa a ser reconhecida como oportunidade de negócio, com potencial para expandir um mercado de proporções ainda não estabelecido, que atinge de forma definida os aspectos econômicos, sociais e culturais da comunidade por ela abrangida, tendo importância relevante no que se refere à preservação do meio ambiente, haja vista que é de interesse comum a manutenção dos aspectos naturais bem como a manutenção e reposição dos estoques pesqueiros.

Considerando-se apenas o universo de peixes esportivos, as águas brasileiras abrigam mais de 40 espécies de peixes de interesse para a pesca esportiva. Em termos de condições naturais, o país oferece tudo o que o pescador pode desejar: rios caudalosos cercados por florestas tropicais, corredeiras, lagos, e mais de $8.000 \mathrm{~km}$ de costa, com uma grande extensão de praias, manguezais e costões sem contar o alto-mar (GUIA BRASILEIRO DE PESCA AMADORA, 1999). 
Diante do potencial de crescimento sócio-econômico proporcionado pela pesca esportiva o Governo Federal criou o Programa Nacional de Desenvolvimento da Pesca Amadora - PNDPA, uma parceria entre o Ministério de Esporte e do Turismo/EMBRATUR e o Ministério do Meio Ambiente/IBAMA, que tem o objetivo de transformar a atividade de pesca amadora em instrumento de desenvolvimento econômico, social e de conservação ambiental (PNDPA). O Programa é aprovado pelo Projeto Pesca Amadora - PNUD, uma parceria como Programa das Nações Unidas para o Desenvolvimento Sustentado.

Entre as ações do PNDPA encontram-se a identificação de áreas com potencial para a pesca amadora e implementação de ações voltadas para a atividade, como, por exemplo, buscar a implementação de estrutura hoteleira e promover o envolvimento e capacitação das populações locais, viabilizando uma nova fonte de renda ou renda alternativa para as comunidades ribeirinhas/costeiras.

Além do diagnóstico das condições de pesca e da necessidade de serviços específicos para a pesca amadora, as prospecções têm desencadeado ações voltadas para a regulamentação, fiscalização, educação ambiental e pesquisa.

Outro objetivo do programa é trabalhar junto aos estados e municípios para a melhoria da regulamentação da atividade, com base na elaboração de legislação de pesca que defina questões como cotas e tamanhos mínimos de captura, licença de pesca amadora, bem como definir, de igual modo, o estabelecimento de lagos, rios ou trechos de rio como áreas reservadas para a pesca amadora.

No PNDA, as áreas são definidas considerando-se critérios como estudo de conservação e grau de fragilidade do ecossistema, importância da pesca comercial para as populações ribeirinhas; presença de estruturas de pesca atuando dentro do conceito pesque e solte. 
O treinamento de guias de pesca é outra atividade contemplada no PNDPA. Nas oficinas de treinamento são ministradas aulas sobre diversos temas visando não só o crescimento pessoal, social e econômico dos guias/piloteiros, mas, também, preparar hotéis e pousadas e estruturas receptivas do turista de pesca para que possam oferecer uma qualidade de serviços cada vez mais elevada. Ganha o indivíduo, o turismo e o meio ambiente, uma vez que, além de temas especificamente voltados para a pesca amadora e turismo, as oficinas também abrangem temas como biologia, ecologia, pesque e solte e geografia, com um enfoque que prioriza a conservação ambiental.

Outro ponto de enfoque prioritário no PNDPA consiste nos trabalhos de educação ambiental voltados para as crianças. As oficinas de "Pesca Infantil" visam transmitir aos futuros pescadores conceitos e técnicas modernas da pesca esportiva, uso de iscas artificiais, noções e cuidados com o meio ambiente, visando tornar a pescaria mais interessante, mais produtiva e mais correta do ponto de vista ambiental.

Em resumo, o destaque do Programa de Desenvolvimento da Pesca Amadora PNDPA está na proposta de atuação conjunta com a sociedade civil no sentido de fortalecer a pesca amadora como atividade importante para o turismo, o comércio e a indústria, e, também, para a conservação do meio ambiente e da cultura e tradição das populações locais, enfocando as seguintes ações:

- Proposição/adequação de instrumentos legais para a pesca amadora.

- Capacitação das populações ribeirinhas/costeiras como guias de pesca.

- Prospecção de novas áreas para a pesca amadora.

- Busca de investimentos para o desenvolvimento do setor.

- Divulgação do Brasil no exterior, visando aumentar o número de turistas estrangeiros que pescam no Brasil.

- Fomento à realização de feiras e torneios de pesca amadora.

- Divulgação da importância da Licença para Pesca Amadora, visando o aumento de pescadores licenciados. 
- Educação ambiental, alertando sobre a necessidade de conservar o meio ambiente e como cada pescador pode ser parceiro dos órgãos ambientais nesse trabalho.

- Melhoria da fiscalização, por meio da transmissão de conhecimentos sobre pesca aos fiscais ambientais.

- Promoção de pesquisas para conhecer melhor a ecologia dos peixes esportivos.

Ao contrário da pesca profissional, as oportunidades advindas com a implantação da pesca amadora têm proporcionado um incremento substancial dos ganhos econômicos para muitas populações, superando, em muito, os ganhos representados pela atividade extrativista. De acordo com MÉLEGA (1998), pescadores-turistas podem representar até 40 vezes mais do que o faturamento com o extrativismo pesqueiro.

Afirma, ainda, que muitas localidades tiveram suas economias drasticamente melhoradas graças ao incremento do segmento da pesca amadora, que deslocou parte do contingente da comunidade que tinha como fonte de renda a pesca profissional para o atendimento ao turista.

Neste processo os governos e entidades particulares da indústria, comércio e serviços, passam a ter na pesca esportiva, novas oportunidades de comercialização e o conseqüente crescimento econômico, formando um filão atrativo de investimentos de caráter nacional.

\subsection{Aspectos Ecológicos do Lago Paranoá}

\subsubsection{Eutrofização}

O Lago Paranoá é um lago artificial construído quando da implantação de Brasília, por meio do barramento do rio Paranoá. Como conseqüência desse 
processo, ao longo do tempo, devido ao crescimento da cidade, passou a receber os impactos originados desta expansão.

Situado na zona urbana de Brasília (15²48'S e 47050’W), o Lago Paranoá, é formado a partir do fechamento da barragem do Rio Paranoá, no ano de 1959. Sua bacia de contribuição drena 1.034,07 $\mathrm{km}^{2}$ e é formada por 21 córregos, com quatro tributários principais: Riacho Fundo, Ribeirão do Gama e Cabeça de Veado (mananciais do Lago Sul); Ribeirão Bananal e Ribeirão do Torto (manancial do Lago Norte). Cada um desses tributários forma um braço do lago. Além dos quatro braços, o lago possui uma zona central que pode ser subdividida em Zona Central Sul, Zona Central Norte e Zona da Barragem (RIBEIRO et al. 2001).

O principal tributário, o Rio Paranoá, nasce dentro do Parque Nacional de Brasília, em um córrego afluente do Ribeirão do Torto, e flui por quase $50 \mathrm{~km}$ até a sua confluência com o Rio São Bartolomeu (DF). Este último corre em direção ao Rio Corumbá (GO), que é afluente do alto Rio Paranaíba (GO - MG), formador do Rio Paraná (Bacia Platina). Sua bacia de captação drena 246 km2 e é formada pela bacia de captação do Lago Paranoá e por alguns pequenos tributários, localizados a jusante da barragem, que afluem ao leito bastante encaixado do baixo Paranoá. (RIBEIRO et al. 2001).

Foram necessárias duas temporadas de chuva para que as águas do novo lago atingissem a cota prevista de 1000 m acima do nível do mar (FERRANTE 2001).

A quase totalidade da documentação da bacia do Rio Paranoá refere-se à bacia do lago que leva o seu nome, e não do rio, que segue cerca de dez quilômetros após a barragem do Paranoá e desemboca no Rio São Bartolomeu (ABERS 2002).

Situado à jusante da cidade de Brasília, o lago do Paranoá tem sofrido de forma intensa os problemas decorrentes da atividade antrópica desenvolvida em sua bacia 
de captação, com reflexos diretos no nível de eutrofização de suas águas, com prejuízos evidentes à sua balneabilidade.

As represas, por se tratarem de um sistema artificial, intermediários entre os rios e lagos, constituem uma unidade de considerável complexidade ecológica cuja evolução é própria e particular.

Discorrendo sobre os efeitos construção de barragens sobre corpos hídricos, TUNDISI (1987) destaca que a ecologia das represas está diretamente relacionada com os sistemas ecológicos da sua bacia hidrográfica de origem como um todo e o entendimento de suas particularidades dependem do acúmulo de informações ecológicas, sociais, econômicas, espaciais e temporais, que são registradas nos reservatórios sob diversas formas: composição da estrutura das comunidades, composição química do sedimento e da água e desenvolvimento de macrófitas aquáticas.

Em função disso, o manejo de reservatórios deve prestigiar técnicas e metodologias adequadas para cada represa, pelo que se fazem necessárias informações ecológicas básicas relacionadas com os processos em vários níveis e as características de evolução desses ecossistemas sob diversos impactos, buscando a compreensão da dinâmica dos processos envolvidos.

A utilização plena dos reservatórios, com a implantação de alternativas adequadas depende de um processo contínuo de acompanhamento que deve possibilitar se conhecer as modificações no sistema biofísico com o decorrer do tempo, e progressivamente, acoplar as estruturas sociais e os usos múltiplos com essas novas características (TUNDISI 1987).

Dentre os processos biológicos que ocorrem com a formação das barragens, a eutrofização de reservatórios é a que apresenta o maior impacto às atividades humanas bem como às comunidades biológicas (TUNDISI 1987). O processo resulta 
em um aumento de nutrientes essenciais para o fitoplâncton e macrófitas aquáticas, principalmente nitrogênio, fósforo, carbono e ferro, que têm como principais causas:

- despejo de esgotos domésticos;

- despejos industriais e detergentes;

- despejo de resíduos de atividades agrícolas;

- poluição do ar e queda de material da atmosfera.

O processo de eutrofização nas represas constitui, sem dúvida, um filtro ecológico muito seletivo com relação à diversidade e sucessão de espécies. As conseqüências da eutrofização nos sistemas aquáticos são, principalmente:

- aumento da biomassa e da produção primária de fitoplâncton;

- diminuição da diversidade de espécies;

- diminuição da concentração de oxigênio;

- diminuição da transparência da água;

- aumento da concentração iônica;

- aumento do fósforo no sedimento;

- aumento da freqüência de florescimento de cianofíceas (algas).

Essas modificações globais são, entretanto, reguladas por uma série de fatores, e um dos mais importantes é o tempo de residência da água na represa, o qual funciona como um sistema de controle da biomassa e da concentração de nitrogênio e fósforo. (TUNDISI 1987).

A poluição do Lago Paranoá por esgotos domésticos, o desmatamento de suas margens e das matas ciliares de seus tributários, os impactos decorrentes da ocupação de sua orla e o assoreamento são condicionantes decisivas para sua degradação ambiental, que se acentuam em função da degradação ambiental decorrente da intensificação do processo de uso e ocupação do solo em toda a bacia (NETTO 2001). 
Segundo BURNETT et al. (2001), os reflexos do processo de eutrofização no Lago Paranoá foram notados inicialmente em meados da década de setenta e foram atribuídos a problemas na limpeza da área a ser submersa (desmatamento incompleto e inadequado), a não remoção de acampamentos e favelas existentes na área a ser inundada. Também o lançamento de esgotos brutos e tratados, o carreamento de nutrientes e adubos pelos tributários e os detritos de toda natureza trazidos pelas águas pluviais, resultantes da atividade humana e rural, acarretaram graves danos ao lago.

Em etapa posterior, mais precisamente em 1987 e 1988, verificou-se a multiplicação indesejada de algas azuis, que liberavam mau cheiro e produziram mortandade de organismos aquáticos, induzida pelo aumento de nutrientes solubilizados, principalmente o fósforo, carreado para o reservatório por meio dos seus tributários, esgotos clandestinos, escoamento superficial e, principalmente, pelos esgotos provenientes das Estações de Tratamento de Esgoto Norte e Sul (BURNETT et al. 2001).

Os estudos que se procederam a partir de então, buscando o efetivo controle do aporte de fósforo na barragem, indicaram a necessidade de alteração do método de tratamento dos esgotos canalizados para as estações de tratamento, medida esta que se tornou realidade a partir de 1993, com a adoção de métodos mais modernos e adequados, que associaram o tratamento biológico com remoção de nutrientes (fósforo e nitrogênio - processo sul africano) seguido do tratamento químico (polimento total - tratamento europeu).

Atualmente, não existe, ao menos em tese, lançamento de esgoto bruto nas águas do Lago Paranoá, sendo que a ETE Sul trata os esgotos provenientes da Asa Sul e das regiões administrativas do Núcleo Bandeirante, Candangolândia, Cruzeiro, parte do Lago Sul e Guará, incluindo o SIA, enquanto a ETE Norte, recebe o restante do Plano Piloto, do Varjão e parte do Lago Norte. 
Associadas a este procedimento, como medida complementar, foram adotadas pela Companhia Energética de Brasília - CEB, a partir de agosto de 1998, medidas de manejo que resultaram na modificação do tempo de residência da água do lago, o que promoveu uma melhoria significativa da qualidade da água, que se mantém até os dias de hoje (BURNETT et al. 2001).

Estudos recentes, entretanto, demonstram que esse equilíbrio é frágil e, se o nível de fósforo superar um determinado limite em qualquer parte do Lago, o efeito "berçário" pode estabelecer uma nova crise. Mesmo com as estações de tratamento, o fósforo ainda chega ao lago, via fontes difusas do sistema de drenagem pluvial, de conexões clandestinas, ou do próprio sistema de tratamento, que não elimina todos os elementos poluidores (ABERS 2002).

Estudos realizados por PINTO e CAVALCANTI (2001) indicam que mantidas as atuais taxas de crescimento da ocupação do solo da bacia de captação do Lago Paranoá, caso não sejam tomadas medidas concretas para redução do fósforo, a capacidade de suporte do lago será superada por volta de 2010 a 2015, representando um retrocesso aos esforços despendidos para a sua recuperação.

Ficou demonstrado, também, que a proliferação de espécies bentófagas, no caso da represa, as tilápias, acelera a ciclagem interna de nutrientes, em especial o fósforo, favorecendo a proliferação de algas indesejáveis (cianobactérias), propiciando, assim, o aparecimento de fenômenos de acelerada eutrofização como os ocorridos em 1977 e 1978, que resultaram na morte de cerca de 300 toneladas de peixes (BURNETT et al. 2001, FONSECA 2001).

O problema está sendo contornado com a adoção de programa de biomanipulação, que tem como objetivo a retirada do excesso populacional desta espécie o que foi ação complementar à melhoria da qualidade da água. 
Aliado à melhoria da qualidade da água do lago no que diz respeito aos índices de eutrofização, melhorias significativas foram sentidas no que diz respeito à contaminação bacteriológica. Atualmente $90 \%$ da área superficial do lago encontrase em condições adequadas para o uso recreativo pela população (BURNETT et al. 2001).

Com o propósito de informar à população quanto à qualidade da água do Lago Paranoá, foi implantado pela CAESB, a partir de 1974, o Programa de Balneabilidade, que, atualmente, produz mapa semanal que enquadra as águas em diferentes classes de uso (Excelente, Muito Boa, Satisfatória e Imprópria), com base na Resolução $n^{\circ}$ 20, de 18.6.1986, do CONAMA - Conselho Nacional de Meio Ambiente.

Outro problema que exigiu medidas de controle foi o crescimento desordenado de plantas aquáticas (Eichhornia crassies), conhecida vulgarmente como aguapé, jacinto d'água e baronesa. Devido a sua elevada taxa de crescimento, grandes extensões do espelho d'água foram por ela cobertos, atrapalhando sobremaneira a navegação e saída dos clubes, além se servir como habitat adequado ao abrigo de répteis, insetos e vetores de doenças, tais como mosquitos e caramujos (BURNETT et al. 2001).

A solução encontrada, e até hoje utilizada, foi a aquisição de embarcação projetada especialmente para a realização da tarefa de retirada mecânica da vegetação. Este equipamento está operando rotineiramente desde 1985 e tem apresentado resultado satisfatório, mantendo sobre controle a expansão dos aguapés.

\subsubsection{Ictiofauna}

A artificialização da paisagem hídrica, associada com a crescente urbanização das margens do Lago do Paranoá, gerou um excedente de lixo e esgoto não 
tratados, processos erosivos crescentes em sua bacia de drenagem, conversão irregular de veredas e matas de galeria, eutrofização (enriquecimento artificial das águas com nutrientes) e sedimentação (assoreamento com sedimentos carreados a partir da bacia de drenagem) dos tributários e da represa, que forçaram profundas alterações nos hábitats aquáticos, nas condições físico-químico das águas e nas relações entre as espécies de peixes, tanto no corpo do reservatório, como nos tributários, a montante, e no Rio Paranoá, a jusante (RIBEIRO et al. 2001).

Segundo AGOSTINHO (1994), o nível de impacto sobre a diversidade biológica, relaciona-se principalmente às características da fauna local, à localização da barragem em relação à área de distribuição das populações, à morfometria da bacia, à existência de outros aproveitamentos a montante, ao desenho da barragem e aos procedimentos operacionais da usina.

No caso do Lago Paranoá a barragem foi construída sobre a antiga Cachoeira do Paranoá que, por sua altura, era uma importante barreira para a dispersão da fauna aquática, determinando um longo período de isolamento das comunidades de peixes do alto Rio Paranoá. Isso explica a baixa similaridade (30\%) entre as comunidades de peixes dos tributários do Lago Paranoá com as demais comunidades de peixes do Distrito Federal (RIBEIRO et al. 2001).

A somatória dessas ocorrências foi fundamental no processo de reestruturação das comunidades de peixes que originalmente ocupavam o Rio Paranoá e determinaram uma perda significativa da biodiversidade. Um dado representativo desta perda, de acordo com RIBEIRO et al. (2001), pode ser ilustrado pelo fato de que, naturalmente, a comunidade de peixes da bacia que forma o Lago Paranoá é formada por 42 espécies, das quais apenas 11 (21\%) adaptaram-se às novas condições ambientais advindas com a formação da barragem.

O Lago Paranoá, segundo a Secretaria de Meio Ambientes e Recursos Hídricos, na atualidade, é colonizado por quatorze espécies de peixes originários de 
outras bacias hidrográficas: brasileiras, africanas, asiáticas, européias e norteamericanas.

Introduzidos progressivamente no lago por intermédio de iniciativas governamentais, bem como introduções não autorizadas, à par dos impactos negativos, como a extinção de algumas espécies nativas, aquelas possibilitaram um incremento considerável no rendimento pesqueiro do lago e, em conseqüência, o desenvolvimento de uma pesca comercial e esportiva.

\subsection{Repovoamento da Barragem}

A ação sinergística e cumulativa das diferentes mudanças ambientais decorrentes da criação de barragens sobre as comunidades aquáticas é marcada pela extinção local de algumas espécies e alteração na abundância da maioria (Araújo-Lima et al. 1995 apud RIBEIRO et al. 2001).

Face aos impactos decorrentes da implantação de empreendimentos hidrelétricos, como medida mitigadora, o Decreto-Lei $n^{\circ} 221$, de 28.2.1967, dispôs sobre a obrigatoriedade da realização de peixamento, ou seja, a introdução maciça de peixes em sistemas represados ou a construção de escadas para peixes migratórios.

Vários países já adotam estratégias para contornar esta situação de perda de biodiversidade. Exemplos bem sucedidos, conforme destaca SIROL (sem data), são identificados no Japão, que possui programas de repovoamento orientados para espécies marinhas comerciais, com destaque para os programas com o olhete (Seriola sp) e o linguado (Paralichthis olivaceus) que, apesar do aumento dos esforços de captura dessas espécies, nas últimas décadas se observa um incremento no nível de captura. 
Outro exemplo importante é o programa de proteção e conservação da população do salmão nos Estados Unidos e no Canadá, onde, graças a medidas definidas de manejo dirigidas a essa espécie, as capturas de salmão pelos povos indígenas (ações voltadas para a questão cultural), frotas pesqueiras e turísticas (econômico) tem apresentado resultados constantes e até, em alguns casos, resultado em aumento da produção do pescado (SIROL).

De acordo com RIBEIRO et al. (2001), a introdução de peixes no Lago Paranoá iniciou-se no ano seguinte do seu enchimento, tendo sido lançados no reservatório, entre março e dezembro de 1960, um total de 145.000 tilápias do Congo (Tilapia rendalli), 6.500 "black-bass" (Micropterus salmoides); 7.000 "bluegill" (Lepomis macrochira); 5.000 mandi amarelo (bagre não identificado) e 12 reprodutores de piapara (espécie da Família Anostomidae - piaus), peixes estes oriundos da estação de piscicultura da Granja do Ipê.

Durante a década de 70, a lista de espécies introduzidas no lago passou também a incluir peixes ornamentais criados por aquaristas amadores. Introduções involuntárias e/ou clandestinas de espadinha (Xiphophorus hellerii e X. maculatus) e "guppy" (Poecilia reticulata) se somaram à lista de peixes amazônicos (tucunaré), norte-americanos (bluegill e black-bass), europeus (carpa comum) e asiáticos (peixe japonês, Carassius auratus) já ocorrentes no Lago Paranoá (RIBEIRO et al. 2001).

O início da década de 80 foi marcado pelos peixamentos do lago com duas espécies amazônicas, o tamoatá (Callychthys callychthys) e o tambaqui (Colossoma macropomum), esta última de relevante interesse para a pesca esportiva, além de uma espécie de camarão de água doce do gênero Macrobrachium, sendo que a primeira conseguiu estabelecer população reprodutiva no reservatório, enquanto, relativamente à segunda espécie, não foram relatadas capturas.

A fim de incrementar a oferta de pescado do Lago Paranoá para valores próximos a 200 ton./ano, com base na produção máxima teórica esperada de 400 
ton./ano (100 kg/ha) projetada para os $40 \mathrm{~km}^{2}$ de espelho d'água, Dornelles e DiasNeto 1985, citados por RIBEIRO et al. (2001), sugeriram o reforço do povoamento do reservatório com carpa comum (Cyprinus carpio) e tucunaré (Cichla ocelaris).

Foi defendida, ainda, pela dupla de pesquisadores, a introdução das carpas chinesa capim (Ctenopharyngodon idella) e prateada (Hyphophthalmichthys molitrix), para combater a poluição orgânica, e o povoamento do reservatório com duas espécies brasileiras de elevado valor comercial e interesse para a pesca esportiva, o pacu (Piaractus mesopotamicus) e o tambaqui (C. macropomum).

A despeito dessas sugestões, somente se tem notícia de duas novas introduções de espécies de peixes ocorridas no Lago Paranoá nesta última década, ambas, de forma não programada. Desde o início da década de 90, alguns exemplares da carpa chinesa prateada, provenientes dos experimentos do Programa de Biomanipulação da CAESB, escaparam de tanques experimentais, gaiolas e limnocurrais e passaram a habitar o espelho d'água do lago.

Outra espécie que passou a habitar o lago, introduzida de forma clandestina, foi o bagre africano (Claria $s p$ ), sendo relatada a sua captura no braço do Riacho Fundo, entre os anos de 1997 e 2000 (RIBEIRO et al. 2001).

Apesar dos escassos programas de repovoamento e reposição dos estoques pesqueiros no corpo da represa, estudos realizados na década de 90 , relativos a biomassa, segundo RIBEIRO et al. (2001), citando Bachmann et al. (1996) e Brabrande et al. (1990), situam o Lago Paranoá entre os ecossistemas de maior produtividade de peixes, quando comparado tanto a lagos tróficos temperados quanto a reservatórios subtropicais, o que justifica a possibilidade do aproveitamento sustentável dos recursos pesqueiros do lago para a atividade da pesca esportiva.

A alteração da população da icitiofauna do Lago Paranoá pode ser observada na Tabela 1 que ilustra a evolução das comunidades entre os anos de 1960 a 1990. 
Tabela 1 -Modificação na Ictiofauna do Lago Paranoá (1960 - 1990)

\begin{tabular}{|c|c|c|c|c|c|}
\hline Espécies & \begin{tabular}{|l} 
Nome \\
popular
\end{tabular} & $\begin{array}{l}\text { Peixame } \\
\text { nto } 1960\end{array}$ & \begin{tabular}{|l} 
Década \\
1970 \\
\end{tabular} & \begin{tabular}{|l} 
Década \\
1980
\end{tabular} & \begin{tabular}{|l} 
Década \\
1990
\end{tabular} \\
\hline \multicolumn{6}{|c|}{ EXÓTICAS } \\
\hline Tilapia rendali & Tilápia & $\mathbf{x}$ & $\mathbf{X}$ & $\mathbf{x}$ & $\mathbf{x}$ \\
\hline Micropterus salmoides & Black Bass & $\mathbf{x}$ & & & \\
\hline Lepmosis macrochira & Blue Gill & $\mathbf{x}$ & $x$ & $\mathbf{x}$ & $\mathbf{x}$ \\
\hline Pimelodus sp. & \begin{tabular}{|l} 
Mandi \\
amarelo \\
\end{tabular} & $\mathbf{x}$ & & & \\
\hline Leporinus sp. & Piapara & $\mathbf{x}$ & & & \\
\hline Cyprinus carpio & Carpa & & $\mathbf{X}$ & $\mathbf{x}$ & $\mathbf{x}$ \\
\hline Carassius auratus & $\begin{array}{l}\text { Peixe } \\
\text { japonês }\end{array}$ & & & & \\
\hline Oreochromis niloticus & Tilápia & & & $\mathbf{X}$ & \\
\hline Cichla ocelaris & Tucunaré & & $\mathbf{X}$ & $\mathbf{x}$ & $\mathbf{x}$ \\
\hline Hypophthalmichthys molitrix & $\begin{array}{l}\text { Carpa } \\
\text { prateada }\end{array}$ & & & & $\mathbf{X}$ \\
\hline Callichthys callichthys & Tamaotá & & & $\bar{X}$ & $\mathbf{X}$ \\
\hline Colossoma macropomum & Lambari & & & $x$ & \\
\hline Clarias sp. & \begin{tabular}{|l} 
Bagre \\
Africano \\
\end{tabular} & & & & $\mathbf{X}$ \\
\hline Xiphophorus heleri & Espadinha & & & $\mathbf{x}$ & \\
\hline \multicolumn{6}{|c|}{ NATIVAS } \\
\hline Steindachnerina sp. & Sanguirú & $\mathbf{x}$ & $\mathbf{x}$ & $\mathbf{x}$ & $\mathbf{x}$ \\
\hline Astyanax scabripinis paranae & Lambari & $\mathbf{x}$ & $\mathbf{x}$ & $\mathbf{x}$ & \\
\hline Geophagus brasiliensis & $\begin{array}{l}\text { Acará } \\
\text { amarelo }\end{array}$ & & & & $\mathbf{x}$ \\
\hline Rhamdia quelen & Bagre & & $\mathbf{x}$ & $\mathbf{x}$ & $\mathbf{x}$ \\
\hline Hoplias malabaricus & Traíra & & $\mathbf{x}$ & $\mathbf{x}$ & $\mathbf{x}$ \\
\hline Hypostomus sp. & Cascudo & & $\mathbf{x}$ & $\mathbf{x}$ & $\mathbf{x}$ \\
\hline Gymnotus carapo & Sarapó & & & $\mathbf{x}$ & \\
\hline Aequidens sp. & Acará preto & & & $\mathbf{x}$ & \\
\hline Hoplerythrinus & Jeju & & & & $\mathbf{x}$ \\
\hline Astyanax bimaculatus & Lambari & & & & $x$ \\
\hline Sinbranchus marmoratus & Muçum & & & & $x$ \\
\hline
\end{tabular}

Fonte: Secretaria de Meio Ambiente e Recursos Hídricos - SEMARH

\subsection{Pesca no Lago Paranoá}

A prática da pesca esportiva no Lago Paranoá, apesar de amplamente praticada pela população do Distrito Federal, principalmente às suas margens, possui poucos registros, pelo que a matéria ficará restrita às atividades relacionadas à pesca profissional. 
Proibida até 1999, segundo levantamento sócio-econômico realizado em 1985, a pesca era praticada por cerca de 100 famílias. Exercida com a utilização de tarrafas, apresentava uma produção total de cerca de 200 toneladas, o que, em média, consiste em dizer uma produtividade de cerca de $45 \mathrm{~kg} / \mathrm{ha} / \mathrm{ano}$, concentradas em espécies exóticas, principalmente carpas e tilápias, representando este última 85\% das capturas (RIBEIRO et al. 2001).

A comercialização do pescado ocorria dentro do Distrito Federal, de forma direta ou por meio de intermediários, representando a principal fonte de renda dessas famílias e possibilidade de alimento barato para a população carente do Distrito Federal.

Com o incremento da fiscalização na década de 90, ocorreu a desestruturação social da atividade, afastando assim, os intermediários, cabendo ao pescador a tarefa da venda do pescado, proporcionando uma renda mensal média, para os que permaneceram na atividade, de até $R \$ 600,00$, sendo que alguns pescadores mais diligentes, chegaram a faturar mais de mil reais/mês, provando ser uma atividade econômica viável e, desde que baseada em estudos técnicos, que indiquem a capacidade de suporte, sustentável (RIBEIRO et al. 2001).

Segundo BURNET et al. (2001), como resultado de anos de pesquisa controlada, ficou demonstrado que a proliferação de espécies bentófagas, no caso da represa, as tilápias, acelera a ciclagem interna de nutrientes, favorecendo a proliferação de algas indesejáveis (cianobactérias), propiciando, assim, o aparecimento de fenômenos de acelerada eutrofização como os ocorridos em 1977 e 1978, que resultaram na morte de cerca de 300 toneladas de peixes.

Em decorrência da pesquisa, a partir de 1999, o processo de biomanipulação foi adotado em escala global no Lago Paranoá, em especial nos braços do Riacho 
Fundo e envolveu dezenas de pescadores, tendo como principal objetivo a retirada do excesso da população de tílápias em áreas susceptíveis à mortalidade maciça.

Como resultado do procedimento, foi possível obter junto ao IBAMA autorização especial para a liberação da pesca profissional no Lago do Paranoá, sendo que hoje existem cerca de quatrocentos pescadores cadastrados, agregados em cooperativa (Lei Distrital no 3.066/2002).

Como resultado das pesquisas realizadas, BURNETT et al. (2001) afirma que a pesca profissional no Lago Paranoá foi uma decisão acertada dos órgãos ambientais do Distrito Federal e mostrou preencher os requisitos necessários para ser utilizada como medida socioambiental: captura concentrada em espécies exóticas que afetam negativamente a qualidade da água; gera empregos diretos e indiretos para a população carente; é rentável economicamente e fornece proteína de alta qualidade e a preços baixos para as populações carentes da região.

\subsection{Legislação Federal sobre a Pesca}

A Lei que dispõe sobre a proteção à fauna Lei $n^{0} 5.197 / 67$, em seu art. $1^{\circ}$, afirma: "os animais de quaisquer espécies, em qualquer fase de seu desenvolvimento e que vivem naturalmente fora do cativeiro, constituindo a fauna silvestre, (...) são propriedade do Estado, sendo proibida a sua utilização, perseguição, destruição, caça ou apanha".

Assim, a União detém o domínio sobre a fauna e esta não constitui bem do domínio privado da Administração Pública ou bem patrimonial, do qual possa utilizarse para praticar atos de comércio. A fauna lhe pertence porque deve ser administrada pelo poder público tendo em vista o interesse coletivo. Por isso é importante classificar-se esse bem como bem de uso comum do povo, no qual a utilidade pública da conservação da fauna constitui uma característica inegável. 
Como qualquer atividade, a pesca esportiva, pelas suas características próprias, recebeu legislação especial complementar. O Decreto Lei nº 221, de 28.2.1967, dispõe sobre o estímulo à pesca e dá outras providências e estabelece, para efeitos legais, que os efeitos do Decreto-Lei, seus regulamentos, decretos e portarias dele decorrentes, se estendem especialmente "as águas interiores do Brasil" (art. 4ª a).

Mais recentemente foi aprovada pelo Instituto Brasileiro do Meio Ambiente e dos Recursos Naturais Renováveis - IBAMA, a Portaria $n^{\circ} 30$, de 23.5.2003, que estabelece definições e normas gerais para o exercício da pesca amadora (esportiva) no território Nacional.

A Portaria no 30 trás em seu bojo, como inovação, a definição e regulamentação das atividades relacionadas a competições de pesca esportiva, cadastro de entidades da pesca amadora, definição e regulamentação inovadora sobre a pesca subaquática e a dispensa do porte da licença de pesca para os aposentados ou pessoas maiores de 65 anos (sexo masculino) e 60 anos (sexo feminino). Os menores de 18 anos também estão dispensados da licença, porém não têm direito à quantidade mínima de pescado.

É importante salientar, que os municípios e estados possuem competência para legislar, observadas as normas de regência, sobre o estabelecimento de cotas e tamanhos mínimos de captura, adequados às suas realidade ecológicas, bem como o estabelecimento de taxas estaduais de licença.

\section{AÇÕES PÚBLICAS}

Conforme já i destacado anteriormente neste texto, explorar o potencial turístico é uma tendência mundial e, no caso de Brasília, uma máxima que se impõe, graças às suas peculiaridades: centro do poder, cidade tombada pelo patrimônio histórico, arquitetura arrojada e belezas naturais. Estas características, se bem trabalhadas, podem transformar Brasília em um grande pólo de atração turística. 
As maiores potencialidades do Lago Paranoá estão relacionadas com o seu uso para a prática de esportes, o lazer, a recreação e o desenvolvimento de atividades voltadas para o turismo, em função de sua beleza e paisagens.

No que tange ao aproveitamento do Lago Paranoá como atrativo turístico, se faz necessário, conforme destaca GAMA (2001), o estabelecimento de programas e políticas que promovam a vocação do Lago Paranoá para a prática de esportes náuticos e a promoção da pesca esportiva, com a definição de áreas específicas para sua prática e a introdução de novas espécies de peixes compatíveis com a ecologia do lago, que se tornariam mais um atrativo para a cidade.

Para tornar real e consolidar estas potencialidades turísticas é preciso superar a visão, até agora predominante, de que o desenvolvimento se dá a partir apenas de um espaço a ser ocupado. É necessário que seja entendido como construção sustentável, envolvendo, politicamente no processo, todos os seus atores e tendo como ponto de partida o necessário equilíbrio entre as dimensões do desenvolvimento e a preservação dos recursos naturais (BEZERRA 2001).

Sob esta ótica, fruto da Conferência das Nações Unidas sobre o Meio Ambiente e Desenvolvimento, realizada no Rio de Janeiro, em 1992, surgiu a Agenda 21, documento que em seu bojo contem os compromissos para a mudança do padrão de desenvolvimento. Apesar de não ser um documento oficial, a Agenda 21 consagra um consenso em torno de princípios universais de sustentabilidade, traduzidos em políticas públicas particulares, conduzidas por governos nacionais em associação com redes de cooperação (BEZERRA 2001).

Para FONSECA (2001) a sustentabilidade do Lago Paranoá depende não apenas do manejo de seu corpo d'água, mas também da gestão do uso do solo na área de sua bacia de captação, e estabelecimento de políticas públicas que democratizem e garantam a utilização do lago para toda a população. 
No caso do tema, objeto deste trabalho (pesca esportiva), não há como desvincular a sua realização, como empreendimento turístico, dos elementos estruturais de apoio e facilitação que atendam de maneira sustentável e satisfatória a demanda interna e externa que se volta para esta atividade de lazer.

Neste contexto, o Plano de Ordenamento e Estruturação Turística de Brasília, denominado Projeto Orla, em sua primeira versão, datada de 1992, foi concebido com o objetivo de incrementar e consolidar a vocação turística do Lago Paranoá para as atividades de lazer. O Projeto Orla propunha, numa primeira etapa "a definição de pólos de atividades voltadas à animação urbana, junto à orla do Lago Paranoá, resgatando-o à população de Brasília e ao turista em geral, promovendo o desenvolvimento social e econômico da cidade, juntamente com a recuperação e a preservação do meio ambiente. A proposta foi desenvolvida tendo como meta permitir que a iniciativa privada sinta-se motivada para assumir a responsabilidade pelos principais investimentos que viabilizem sua implantação" (OLIVA et al. 2001).

O projeto, conforme destaca OLIVA et al. (2001), previa a implantação de 10 pólos de atividades com uma área construída estimada em $780.000 \mathrm{~m}^{2}$. Segundo cálculos da época, o custo total das edificações desses complexos atingiria cerca de 390 milhões de dólares, sendo previsto o emprego, para a fase de implementação de sua estrutura física, de cerca de 166 mil horas/homem/ano e uma geração de empregos permanentes, diretos e indiretos na ordem de 30.000 empregos.

A proposta de aproveitamento da orla do Lago Paranoá veio ao encontro da tendência urbanística moderna de resgatar as orlas de praias, rios e lagos, transformando-os em significativos espaços urbanos, onde as pessoas encontramse, atraídos pelo fascínio que a água exerce sobre o homem.

O projeto foi atualizado em 1995, ganhando mais um pólo e implantação de ganhando um calçadão, interligando os pólos, onde irão ser implementadas atividades culturais, comerciais de hospedagem e de lazer. Pelo projeto, em cada 
pólo permitiu-se o máximo possível de atividades complementares possibilitando maior dinâmica e variedade na sua utilização diurna e noturna, consolidando, assim, a vocação turística do Lago Paranoá (OLIVA et al. 2001).

\section{CONSIDERAÇÕES FINAIS}

O turismo, como fator de geração de renda, empregos e fomento do desenvolvimento local e regional, é imprescindível para a sustentabilidade econômica de Brasília, por meio da exploração do segmento de turismo históricocultural, místico e ecológico.

Com base na pesquisa feita na literatura pertinente, conclui-se que o Lago Paranoá apresenta potencial de aproveitamento para o turismo ecológico. Enfatiza-se os esportes náuticos, a pesca esportiva, o lazer a recreação em função de sua beleza e paisagem.

O desenvolvimento da atividade da pesca esportiva no Lago Paranoá deve constituir-se em uma política pública, com legislação regulamentadora adaptada ao seu potencial. Faz-se necessário o estabelecimento de cotas de captura ou simplesmente o emprego do "pesque e solte", com sustentabilidade ecológica. Estas ações devem estar sob permanente fiscalização pelo poder público.

Devem ser estabelecidas políticas de gestão que democratizem a utilização do Lago Paranoá possibilitando o acesso da população as suas margens e que dirimam os conflitos entre os moradores ocupantes da orla do Lago e seus usuários. Sugerese a instalação de instrumentos de apóio e lazer que fortaleçam os esportes relacionados à pesca, sem perder de vista a integridade dos ecossistemas que o compõem assim como sua biodiversidade e balneabilidade. 


\section{REFERÊNCIAS BIBLIOGRÁFICAS}

ABERS, Rebecca. Bacia do Rio Paranoá, Projeto marca d'água. Relatórios preliminares. Núcleo de Pesquisa em Políticas Públicas, Universidade de Brasília, 2002.

AGOSTINHO, A. A.. Considerações sobre a atuação do setor elétrico na preservação da fauna aquática e dos recursos pesqueiros. In: Seminário Sobre a Fauna Aquática e o Setor Elétrico Brasileiro. Reuniões Temáticas Preparatórias. Caderno I. Fundamentos, Rio de Janeiro, 1994.

ALBRECHT, K. Virando a Pirâmide de Cabeça para Baixo. In Revolução nos Serviços. São Paulo: Pioneira, 1992.

AMARAL, C. Ecoturismo na Bahia. Salvador, BA: SEBRAE, 1995.

ARENDIT, E. J. A. Introdução à Economia do Turismo. São Paulo, Alinea, 1999.

BARRETO, M. Turismo, Legado Cultural. Campinas: ed. Papirus, 1998.

BENI, M. C. Análise Estrutural do Turismo. São Paulo: SENAC, 1998.

BEZERRA, M. C. L., "Planejamento estratégico e participativo", In: Fonseca, Fernando (org.) Olhares Sobre o Lago Paranoá. Brasília, Secretaria de Meio Ambiente e Recursos Hídricos, 2001.

BURNETT, J. A. , MATTOS, S. P. e AZZOLIN, N. M.P. "Intervenções da Companhia de Saneamento", In: Fonseca, Fernando (org.) Olhares Sobre o Lago Paranoá. Brasília, Secretaria de Meio Ambiente e Recursos Hídricos, 2001.

CASTELLI, Geraldo. Turismo atividade marcante do século XX. Caxias do Sul: EDUCS, 1996.

CEBALLUS-LASCURÁIN, H. "O Ecoturismo como um fenômeno mundial", In:

Ecoturismo: Um guia para planejamento e gestão, Kreg Lindberg, Donald E. Hawkins (orgs), 4ª ed., São Paulo, Ed. Senac, 2002.

CHRISTALLER, W. Some Considerations of Tourism Location in Europe: The

Peripheral Regionais - Underdeveloped Countries - Recreation Areas. In:

Regional Science Association. XII Luno Congress. Papers p. 95-105, 1963.

EMBRATUR, Estudos do Turismo Brasileiro. Ecoturismo nas Regiões Sul e Centro-

Oeste. Brasília, 1999. 
FERRANTE, J. E. T.; R. L., e Netto, P. B. "Meio Físico”, In: Fonseca, Fernando (org.) Olhares Sobre o Lago Paranoá. Brasília, Secretaria de Meio Ambiente e Recursos Hídricos, 2001.

FONSECA, F. O., "Manejo dos Peixes", in: Fonseca, Fernando, org., Olhares Sobre o Lago Paranoá. Brasília, Secretaria de Meio Ambiente e Recursos Hídricos, 2001.

GAMA, J. "Setor de Turismo", In: Fonseca, Fernando (org.) Olhares Sobre o Lago Paranoá. Brasília, Secretaria de Meio Ambiente e Recursos Hídricos, 2001.

GUIA BRASILEIRO DE PESCA AMADORA. Brasília; PNDA, 1999.

LINDBERG, K. e HUBER, R. M. Questões econômicas relativas à gestão do ecoturismo In: Ecoturismo: Um guia para planejamento e gestão, Kreg Lindberg, Donald E. Hawkins (orgs), 4ª ed., São Paulo, Ed. Senac, 2002.

MCLNTYRE, G. Desarrollo Turístico Sostenible. Guía para Planificadores Locales. Madrid - Espanha: OMT / WTO / BTO. 1ª edição, 1993.

MÉLEGA, P., artigo publicado na Revista Troféu Pesca, Ano 26, no 216, 1998. MCLNTYRE, George. Desarrollo Turístico Sostenible. Guía para Planificadores Locales. Madrid - Espanha: OMT / WTO / BTO. $1^{\text {a }}$ edição, 1993.

NETTO, P. B. "Sustentabilidade ameaçada", In: Fonseca, Fernando (org.) Olhares Sobre o Lago Paranoá. Brasília, Secretaria de Meio Ambiente e Recursos Hídricos, 2001.

NICOLETTI, L. Turismo e desenvolvimento local sustentável, in Cultura do Turismo: desafios e práticas socioambientais. Montoro, T. S. (org). Brasília: Thesaurus, 2003.

OlIVA, A.. Q.; CAVAlCANTE, C. V.; FONSECA, F. O.; NETTO, P. B. e OGLIARI. T. C., "Planos urbanísticos governamentais", In: Fonseca, Fernando (org.) Olhares Sobre o Lago Paranoá. Brasília, Secretaria de Meio Ambiente e Recursos Hídricos, 2001.

PINTO, M. A. T. e CAVALCANTI, C. G. B. "Uso e Ocupação do Solo e a Qualidade das Águas", In: Fonseca, Fernando (org.) Olhares Sobre o Lago Paranoá. Brasília, Secretaria de Meio Ambiente e Recursos Hídricos, 2001.

PNDPA - Programa Nacional de Desenvolvimento da Pesca Esportiva. 
RIBEIRO, M. C. L. B., STARLING, F.L.R., WALTER, T. e FARAH, E.M., "Evolução da comunidade de peixes do Lago Paranoá", in: Fonseca, Fernando, org., Olhares Sobre o Lago Paranoá. Brasília, Secretaria de Meio Ambiente e Recursos Hídricos, 2001.

RUSCHMANN, D. V. M., Turismo e Planejamento Sustentável. São Paulo: Papirus, 1997.

SIROL, R.N. (sem data). Conservação e Manejo da Ictiofauna, disponível na Internet em: (www.fmvz.unesp.br).

TUNDISI, J, G., 1987. Ecologia, limnologia e aspectos socioeconômicos da construção de hidrelétricas nos trópicos. Biblioteca Virtual de Tropicologia. Conferência, disponível na Internet em: (www.tropicologia.org.br).

YÁZIGI, E., et al. Turismo: Espaço, Paisagem e Cultura; São Paulo: Hucitec, 1996. 